\title{
Review \\ Metabolic syndrome in rheumatic diseases: epidemiology, pathophysiology, and clinical implications
}

\author{
Prodromos I Sidiropoulos, Stylianos A Karvounaris and Dimitrios T Boumpas
}

Department Rheumatology, Clinical Immunology and Allergy, University Hospital, Medical School, University of Crete, 1, Voules Str., Heraklion 71110, Greece

Corresponding author: Prodromos I Sidiropoulos, sidiropp@med.uoc.gr

Published: 8 May 2008

This article is online at http://arthritis-research.com/content/10/3/207

(C) 2008 BioMed Central Ltd
Arthritis Research \& Therapy 2008, 10:207 (doi:10.1186/ar2397)

identify patients who will need lifestyle modification alone from those who will benefit from additional drug therapy.

Epidemiological studies have shown that patients with chronic rheumatic diseases have an increased risk for CVD morbidity and mortality but the pathogenetic factors involved are not yet fully understood. MetS may provide an additional link between accelerated atherosclerosis and inflammation in these diseases.

In this review, we start with a discussion of MetS and its working definitions. Next, we examine recent data about the pathophysiology and epidemiology and their clinical significance in reference to CVD risk assessment. We conclude with a critical analysis of studies addressing the prevalence and significance of MetS in patients with rheumatic diseases.

\section{Metabolic syndrome: overview and proposed criteria}

In 1988, Reaven [1] proposed that insulin resistance is central to the etiologies of T2DM, hypertension, and coronary artery disease. In the ensuing years, the concept of insulin resistance and associated metabolic abnormalities leading to increased risk of CVD became known as insulin resistance/ MetS. A few years later, Barker and colleagues [2] reported an association between low birth weight and increased risk for MetS.

MetS describes a constellation of cardiovascular risk factors such as atherogenic dyslipidemia (increased free fatty acids,

AS = ankylosing spondylitis; CCA-IMT = carotid artery intima-media thickness; CRP = C-reactive protein; CVD = cardiovascular disease; DAS28 = disease activity index of 28 joint counts; ERK = extracellular signal-regulated kinase; GLUT4 = glucose transporter 4; HDL = high-density lipoprotein; HOMA-S = homeostatic model assessment of insulin sensitivity; hsCRP = high-sensitivity C-reactive protein; IDF = International Diabetes Federation; IFG = impaired fasting glucose; IRS = insulin receptor substrate; LDL = low-density lipoprotein; MAP = mitogen-activated protein; $\mathrm{MetS}=$ metabolic syndrome; NCEP = National Cholesterol Education Program; NEFA = non-esterified fatty acid; PI-3 kinase = phosphatidylinositol 3-kinase; QUICKI = quantitative insulin sensitivity check index; RA = rheumatoid arthritis; RR = relative risk; SLE = systemic lupus erythematosus; T2DM = type 2 diabetes mellitus; TNF- $\alpha=$ tumor necrosis factor-alpha; WHO = World Health Organization. 
Table 1

\begin{tabular}{|c|c|c|}
\hline World Health Organization & National Cholesterol Education Program & International Diabetes Federation \\
\hline $\begin{array}{l}\text { Diabetes or impaired fasting glycemia or } \\
\text { impaired glucose tolerance or insulin resistance } \\
\text { (hyperinsulinemic, euglycemic clamp-glucose } \\
\text { uptake in lowest } 25 \% \text { ) }\end{array}$ & & 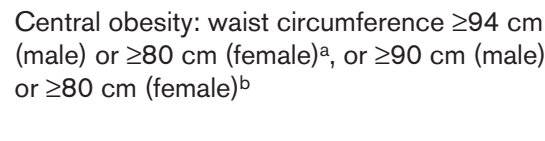 \\
\hline Plus two or more of the following & Three or more of the following & Plus two or more of the following \\
\hline $\begin{array}{l}\text { Obesity: body mass index }>30 \text { or waist-to-hip } \\
\text { ratio }>0.9 \text { (male) or }>0.85 \text { (female) }\end{array}$ & $\begin{array}{l}\text { Central obesity: waist circumference } \\
>102 \mathrm{~cm} \text { (male) or }>88 \mathrm{~cm} \text { (female) }\end{array}$ & $\begin{array}{l}\text { Fasting plasma glucose } \geq 5.6 \mathrm{mmol} / \mathrm{L} \text { or } \\
\text { medication }\end{array}$ \\
\hline $\begin{array}{l}\text { Dyslipidemia: triglycerides } \geq 1.7 \mathrm{mmol} / \mathrm{L} \text { or } \\
\mathrm{HDL} \text { cholesterol }<0.9 \mathrm{mmol} / \mathrm{L} \text { (male) or } \\
<1.0 \mathrm{mmol} / \mathrm{L} \text { (female) }\end{array}$ & $\begin{array}{l}\text { Hypertriglyceridemia: triglycerides } \\
\geq 1.7 \mathrm{mmol} / \mathrm{L}\end{array}$ & $\begin{array}{l}\text { Hypertriglyceridemia: triglycerides } \\
\geq 1.7 \mathrm{mmol} / \mathrm{L} \text { or medication }\end{array}$ \\
\hline Hypertension: blood pressure $\geq 140 / 90 \mathrm{~mm} \mathrm{Hg}$ & $\begin{array}{l}\text { Low HDL cholesterol: }<1.0 \mathrm{mmol} / \mathrm{L} \text { (male) } \\
\text { or }<1.3 \mathrm{mmol} / \mathrm{L} \text { (female) }\end{array}$ & $\begin{array}{l}\text { Low HDL cholesterol: }<1.0 \mathrm{mmol} / \mathrm{L} \text { (male) or } \\
<1.3 \mathrm{mmol} / \mathrm{L} \text { (female) or medication }\end{array}$ \\
\hline \multirow[t]{2}{*}{ Microalbuminuria: albumin excretion $>20 \mu \mathrm{g} /$ minute } & $\begin{array}{l}\text { Hypertension: blood pressure } \\
\geq 130 / 85 \mathrm{~mm} \mathrm{Hg}\end{array}$ & $\begin{array}{l}\text { Hypertension: blood pressure } \\
\geq 130 / 85 \mathrm{~mm} \mathrm{Hg} \text { or medication }\end{array}$ \\
\hline & Fasting plasma glucose $\geq 6.1 \mathrm{mmol} / \mathrm{L}$ & \\
\hline
\end{tabular}

aEuropeans, Sub-Saharan Africans, and Eastern Mediterranean and Middle East (Arab) populations; bSouth Asians and Ethnic South and Central Americans. HDL, high-density lipoprotein.

elevated triglycerides, low high-density lipoprotein [HDL] cholesterol levels, and increased small dense low-density lipoprotein [LDL] and apolipoprotein B levels), central obesity, insulin resistance, disturbed glucose metabolism (T2DM, impaired glucose tolerance, and impaired fasting glycemia), and hypertension [3]. Features like a systemic pro-inflammatory state, accelerated hemostasis, and impaired fibrinolysis, though typically associated with the syndrome, are not included in the diagnostic criteria.

Despite abundant research, there has been a lack of consensus regarding the optimal definition and as a result several criteria have been proposed. The primary goal of all of these definitions is to identify individuals at increased risk for CVD and to enable the initiation of lifestyle changes to decrease this risk. The three most widely used definitions are those from the World Health Organization (WHO) [4], the National Cholesterol Education Program (NCEP) [5], and the International Diabetes Federation (IDF) [6] (Table 1). Under the WHO criteria, a disturbance of glucose/insulin metabolism must be present and thus MetS and diabetes are considered to be intersecting diagnostic categories. On the other hand, according to the NCEP criteria, MetS is a precursor to, but does not include, T2DM. The WHO definition is better suited as a research tool, whereas the NCEP definition is simpler and therefore more useful for clinical practice. The most recently proposed criteria released by the IDF include gender- and ethnic group-specific increased waist circumference as a major criterion, underlining the crucial importance of central obesity in MetS.
Although these criteria are in widespread use, they are currently the subject of intense debate since they do not result from a prospective study nor do they represent the outcome of an evidence-based process. For example, there is much criticism about the reduction of the waist cutoff criterion in men from 102 to $94 \mathrm{~cm}$ in the IDF guidelines. As expected, this reduction has considerably increased the number of patients being diagnosed with the syndrome when epidemiologic evidence supports the view that cardiovascular and overall mortality rates are more consistently increased when using a waist cutoff of $102 \mathrm{~cm}$ rather than $94 \mathrm{~cm}$ [7]. Similarly, reducing the threshold for impaired fasting glucose (IFG) from $6.1 \mathrm{mmol} / \mathrm{L}$ (according to NCEP criteria) to $5.6 \mathrm{mmol} / \mathrm{L}$ (in the IDF guidelines) did not substantially change the hazard ratio for risk of coronary heart disease, although it did increase the number of individuals identified [8].

\section{Pathophysiology: complementary roles of insulin resistance and abdominal obesity Insulin signaling}

Since insulin resistance is a key feature of this syndrome, a brief overview of insulin signaling is crucial to the understanding of MetS. The insulin receptor has an intrinsic tyrosine kinase activity. Binding of insulin to its receptor induces both autophosphorylation and phosphorylation of tyrosine residues on insulin receptor substrate (IRS)-1 to IRS-4 proteins, thus initiating the intracellular signaling cascade [9]. The two major pathways of insulin signaling are the phosphatidylinositol 3-kinase ( $\mathrm{Pl}-3$ kinase) and the mitogen-activated protein (MAP) kinase. The Pl-3 kinase pathway is initiated by tyrosine phosphorylation by a member 


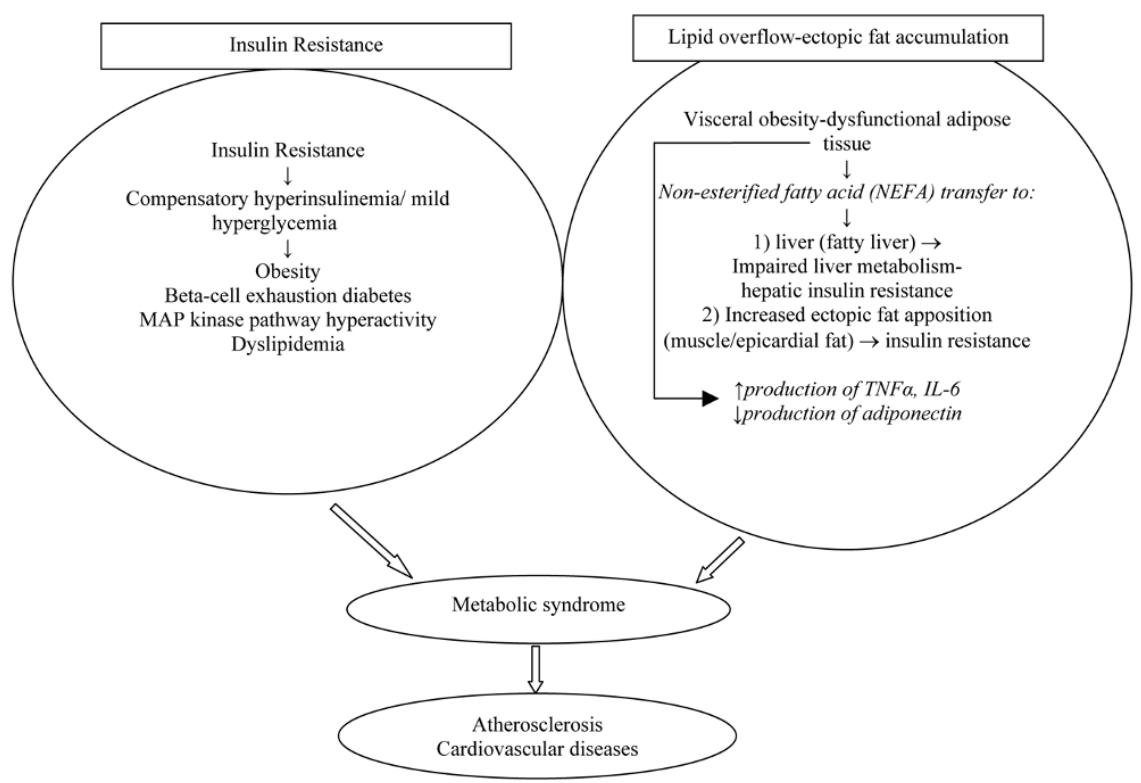

Pathophysiology of the metabolic syndrome: both insulin resistance and lipid overflow contribute to MetS evolution. IL-6, interleukin-6; MAP, mitogen-activated protein; TNF- $\alpha$, tumor necrosis factor-alpha.

of the IRS proteins, which associates with the $\mathrm{p} 85$ regulatory subunit of PI-3 kinase, leading to activation of the enzyme. This pathway results in the activation of Akt and other downstream effector molecules that mediate the metabolic response to insulin; this includes, among others, the translocation of the glucose transporter 4 (GLUT4) to the membrane. On the other hand, the MAP kinase pathway begins with phosphorylation of Shc, Grb2/Sos and ras and results in the activation of extracellular signal-regulated kinase (ERK)-1 and ERK-2. Activated ERKs, which are a type of MAP kinase, mediate the mitogenic and pro-inflammatory responses of insulin signaling. In patients with obesity or T2DM who have profound insulin resistance, the pathways leading to the activation of $\mathrm{PI}-3$ kinase are blocked, possibly through serine phosphorylation of the insulin receptor and/or IRS proteins, whereas the MAP kinase pathway remains open and may even be hypersensitive [10].

\section{Inflammatory cytokines and insulin resistance}

Inflammatory cytokines like tumor necrosis factor-alpha (TNF- $\alpha$ ) can induce insulin resistance and suppression of Glut4 expression by inhibiting insulin receptor autophosphorylation [11] or by inducing serine phosphorylation of IRS-1 [12]. Interleukin-6 also inhibits insulin signal transduction in hepatocytes. This effect seems to be related to SOCS-3 (suppressor of cytokine signalling-3), a protein that associates itself with the insulin receptor, inhibits its autophosphorylation, the tyrosine phosphorylation of IRS-1, the association of the p85 subunit of PI-3 kinase to IRS-1, and the subsequent activation of Akt [13]. Leptin produced by adipose tissue may contribute to insulin resistance through phosphorylation of serine residues of IRS-1 [14]. The involvement of inflammatory cytokines in insulin resistance is very important for two reasons. First, it connects adipose tissue-a major source of inflammatory cytokines in patients with abdominal obesity [15]-with insulin resistance and MetS. Second, it provides a plausible explanation for the interplay between chronic inflammatory diseases (like rheumatoid arthritis [RA]) and MetS/CVD. Insulin resistance may contribute to the pathogenesis of MetS through hyperglycemia, compensatory hyperinsulinemia, and unbalanced insulin action. Among them, hyperinsulinemia seems to be the most important factor (Figure 1).

\section{Abdominal obesity and insulin resistance}

Although obesity is a major contributor to MetS pathophysiology, it is not the sole factor nor is it a direct consequence of insulin resistance [16]. Thus, patients with mutations in insulin receptor or autoantibodies to insulin receptor may exhibit huge increases in plasma insulin (up to 100-fold) but typically have no obesity, hypertension, or atherogenic dyslipidemia [17]. On the other hand, abdominal obesity-the most prevalent component of MetS-is associated with atherogenic and diabetogenic abnormalities. There are data supporting that abdominal obesity does not represent a consequence of MetS but rather is a causal factor [18]. In individuals with visceral obesity (due to a surplus of energy), hypertrophic adipocytes are characterized by a hyperlipolytic state that is resistant to the antilipolytic effect of insulin [19]. The non-esterified fatty acids (NEFAs) 
Table 2

\begin{tabular}{lccc}
\multicolumn{4}{l}{ Prevalence of metabolic syndrome in different countries according to the National Cholesterol Education Program criteria } \\
\hline Age group, years & Country & Percentage in males & Percentage in females \\
\hline$>20$ & US & 24 & 23.7 \\
$>18$ & Greece & 24.2 & 22.8 \\
$20-80$ & Cyprus & 26.5 & 18.3 \\
$>20$ & Italy & 22.3 & 27.2 \\
$>20$ & India & 22.9 & 39.9 \\
$>20$ & Iran & 24 & 42 \\
$>25$ & Poland & 16.2 & 20.9 \\
$>25$ & North Jordan & 28.7 & 40.9 \\
$35-74$ & China & 9.8 & 17.8 \\
$55-74$ & Germany & 28 & 24 \\
$50-69$ & Ireland & 21.8 & 21.5 \\
70 & Sweden & 26.3 & 19.2 \\
\hline
\end{tabular}

produced in excess flux to the liver where they may impair liver metabolism (liver insulin resistance); more specifically, they increase hepatic glucose production (contributing to hyperglycemia), decrease apolipoprotein B degradation, and increase triacylglycerol-rich lipoproteins [20]. In parallel, the ectopic accumulation of lipids within muscles renders myocytes insulin-resistant, thus contributing to defective glucose metabolism. In addition to NEFA overproduction, visceral fat may contribute to MetS through its action as an endocrine organ that produces - among others - proinflammatory cytokines like TNF- $\alpha$ and interleukin-6 (Figure 1). In obesity, the accumulation of macrophages in abdominal fat contributes to pro-inflammatory cytokine production [15]. Moreover, in obese individuals, serum levels of adiponectin that may facilitate insulin signaling in vitro - are decreased [21]. Overall, these data support a role of the expanded visceral adipose tissue leading to altered NEFA metabolism and pro-inflammatory profile, contributing to both insulin resistance and MetS.

\section{Epidemiology}

MetS is widespread throughout the world and its prevalence is expected to increase dramatically in the ensuing years $[22,23]$. This increase is associated with the global epidemic of obesity [24]. Irrespective of the definition of MetS employed, its prevalence in the general population is high, increases with age, and varies with gender and ethnicity. Similar to the trend in adults, there is currently an alarming increase in children and young adults [25]. The overall prevalence of MetS in the US is currently estimated at $24 \%$ and increases to $44 \%$ in adults who are over 60 years. Since several definitions of the syndrome are in use, it is difficult to compare prevalence and impact between countries.
Comparisons of published prevalence for different populations are presented in Table 2.

\section{Clinical significance}

In view of the controversy about the clinical criteria and the lack of a unifying pathophysiologic process, the clinical significance of MetS has not been universally accepted [26]. Thus, the US Food and Drug Administration does not consider MetS as a distinct disease entity. Similar statements cautioning against the premature wide adoption of MetS in clinical practice have been made by the American Diabetes Association and the European Association for the Study of Diabetes, which suggest that it requires further study before its designation as a syndrome is truly warranted and at the same time warn physicians against labeling patients with this term. Nevertheless, in the US, a version of MetS has an ICD-9 (International Statistical Classification of Diseases and Related Health Problems, ninth revision) code (277.7), which permits health care reimbursement.

Despite the aforementioned criticisms, numerous published clinical studies have established the association of MetS with an increased risk of both diabetes [27,28] and CVD [29,30]. A recent meta-analysis of 21 studies, by Galassi and colleagues [31], demonstrated that individuals with MetS compared with those without had an increased all-cause mortality (relative risk [RR] 1.35) and CVD (RR 1.74) as well as an increased incidence of CVD (RR 1.53), coronary heart disease (RR 1.52), and stroke (RR 1.76). Several studies have also shown that MetS confers an increased risk for the development of T2DM, with a variety of RR estimates ranging from 3.5 in the WOSCOPS (West of Scotland Coronary Prevention Study) [32] up to 6.3 in the San Antonio Heart 
Study [33] and 17.9 with greater than or equal to 4 MetS traits in the Beaver Dam Study [33,34]. On the other hand, there are notable exceptions to the large body of evidence documenting the adverse impact of MetS-at least in selected groups of patients. Bruno and colleagues [35] demonstrated that elderly patients with MetS had comparable hazard ratios for all-cause and CVD mortality compared with subjects without the syndrome. Finally, Protopsaltis and colleagues [36], in a recently published study, proposed that MetS per se at baseline or combinations of its components do not predict the development of ischemic stroke in T2DM patients. Accordingly, Bertoni and colleagues [37] found that, although insulin resistance was associated with increased subclinical atherosclerosis, the association was not independent of the risk factors that comprise MetS.

An important clinical question is whether the presence of MetS per se adds to CVD prediction beyond the contribution of the individual risk factors. Sattar and colleagues [32] showed that MetS was not a significant predictor of coronary heart disease when adjusted for its component factors in a multivariate model. Two cross-sectional studies showed that the impact of the syndrome on CVD was greatly attenuated in a multivariate analysis by controlling for certain of its components, thereby suggesting that the whole is not greater than its parts $[38,39]$. Moreover, in a prospective study of diabetic and non-diabetic subjects free of CVD and followed for an average of 11 years, the risk of incident coronary heart disease associated with the syndrome was no greater than that explained by the presence of its components [8]. These studies suggest that the syndrome itself conveys no greater information than the sum of its component risk factors.

\section{Metabolic syndrome and other risk assessment algorithms}

Although the presence of clinical criteria for MetS is predictive of an increased relative CVD risk, MetS should not replace the need to assess overall cardiovascular risk based on well-established CVD risk factors such as age, gender, smoking, blood pressure, LDL cholesterol, and diabetes [40]. It has also been argued that current risk assessment algorithms such as the Framingham Heart Study calculator [41] and UK Prospective Diabetes Study risk model [42] largely capture the risk associated with MetS.

Several studies have compared the predictive value of MetS with that of the Framingham risk prediction model. Girman and colleagues [43] showed that the increased event rate in subjects with MetS remained significant after adjustment for the Framingham 10-year risk, suggesting that the syndrome carries an additional risk not captured by the Framingham risk scoring. Moreover, a clear gradation in the risk of coronary heart disease outcome is evident with each additional component of MetS; men with three or more components and women with two or more components are at statistically elevated risk [8].

\section{Therapeutic interventions}

A 10-year risk assessment is needed in all those individuals who have MetS. If the 10-year risk is high, drug therapy to modify CVD risk factors might be required, whereas if the risk is low, therapeutic lifestyle modification is the first-line therapy [44]. Lifestyle modification, including both weight reduction and increased physical activity, is the cornerstone of treatment for MetS. Although it may not modify any given risk factor as much as a particular drug will, it is beneficial since it produces moderate reduction in all metabolic risk factors [45]. There is general agreement that persons with MetS should adhere to a set of dietary principles: low intake of saturated fats, trans fats, and cholesterol; reduced consumption of simple sugars; and increased intake of fruits, vegetables, and whole grains [44]. Caloric intake should be reduced by 500 to 1,000 calories per day to produce a weight loss of 0.5 to $1.0 \mathrm{~kg}$ per week. A reasonable goal for most individuals is moderate exercise such as walking for 30 minutes per day at least 5 days per week [45].

Pharmacotherapy involves the aggressive management of well-established risk factors. For dyslipidemia, a statin or a fibrate might be a reasonable treatment. Recently, a study showed that after 36 weeks of treatment with either simvastatin or atorvastatin, almost $50 \%$ of patients with MetS no longer met the classification criteria. Mild elevations of blood pressure can often be controlled with lifestyle changes, but if hypertension persists antihypertensive drugs are usually required [46]. Some investigators believe that angiotensinconverting enzyme inhibitors or angiotensin-receptor blockers are better first-line therapy for MetS patients, especially when T2DM is present, but the issue of the most effective drug has not been entirely resolved. For insulin resistance, metformin or a thiazolidinedione might be considered. Yet at the same time, it is unknown whether treating insulin resistance itself would be of value in preventing CVD in all patients or in a subset of MetS patients. Preliminary reports indicate that metformin or thiazolidinediones also reduce the risk for T2DM in people with IFG or impaired glucose tolerance and improve insulin sensitivity $[47,48]$.

Because of the strong association between MetS, CVD, and diabetes, there is urgent need for strategies to prevent the emerging global epidemic. Additional research is needed to determine whether treatment of underlying causes of MetS (for example, insulin resistance in the absence of hyperglycemia) results in better outcome beyond the levels achieved by interventions that target conventional cardiovascular risk factors. Until randomized controlled trials have been completed, there is no appropriate pharmacological treatment for MetS, nor should it be assumed that pharmacological therapy to reduce insulin resistance will be beneficial to patients with the syndrome. Thus, treatment should be aimed at well-established risk factors. 


\section{Rheumatic diseases: cardiovascular burden and metabolic syndrome}

Inflammation is a key feature of obesity and T2DM [49] while patients with chronic inflammatory diseases, like RA or systemic lupus erythematosus (SLE), have an increased risk for CVD [50,51]. RA patients have almost a four-fold increase in cardiovascular events and most importantly this increased risk ratio is independent of traditional risk factors for CVDs. CVDs are the most common cause of death, with approximately $40 \%$ of deaths in RA patients attributed to CVD [52]. It has been proposed that pathogenetic mechanisms attributed to the underlying disease or its treatments are associated with premature atherosclerosis [53]. Although the exact mechanism promoting atherosclerosis in RA remains to be defined, chronic inflammation may alter vascular endothelial biology to a pro-thrombotic/proatherogenic state [54].

Similarly to patients with RA, those with SLE have a higher risk for myocardial infarctions, which is even higher in younger patients (up to an eight-fold increase) [55]. Approximately $25 \%$ of deaths in SLE are attributed to CVD morbidity, which is the leading cause of death. More importantly, although symptomatic coronary disease is not uncommon $6 \%$ to $15 \%)$, subclinical atherosclerosis assessed by non-invasive techniques [stress studies using technetium $99 \mathrm{~m}$ sestamibi single-photon emission tomography (SPECT)] is much higher and observed in upto $42 \%$ of asymptomatic SLE patients [56]. Interestingly, although SLE patients have a high prevalence of traditional risk factors for atherosclerosis [57], the rate of vascular events has been found to be more than seven times that attributed to traditional risk factors [58]. These results suggest the importance of disease-associated factors (like antiphospholipid antibodies) or treatments (like steroids) in the evolution of atherosclerosis.

Several groups have assessed insulin resistance and MetS in patients with rheumatic diseases (Table 3). Homeostatic model assessment of insulin sensitivity (HOMA-S) and the quantitative insulin sensitivity check index (QUICKI) are indices most often applied for insulin sensitivity; homeostatic model assessment of insulin resistance (HOMA-IR) and homeostatic model assessment of beta cell function (HOMA-B) are indices applied for insulin resistance and beta cell function, respectively.

\section{Rheumatoid arthritis: insulin resistance and metabolic syndrome}

Dessein and colleagues [59] reported that RA patients have lower insulin sensitivity (assessed by QUICKI) compared with osteoarthritis patients ( $n=39$ in both groups; $P<0.05)$, but after controlling for C-reactive protein (CRP) levels, QUICKI was comparable between the two groups. Glucocorticoids were not associated with decreased insulin sensitivity, whereas other factors (waist circumference, CRP, HDL cholesterol, and triglycerides) were associated. Several years later, the same group found that RA patients with high-grade inflammation (high-sensitivity CRP [hsCRP] greater than $1.92 \mathrm{mg} / \mathrm{L})$ had higher insulin resistance compared with those with lower hsCRP [60]. However, in mixed regression models, only abdominal obesity and the patient's assessment of disease activity were predictors of insulin resistance, whereas other disease activity indices (CRP, erythrocyte sedimentation rate, and disease activity index of 28 joint counts [DAS28]) were not. The authors concluded that modifiable factors like obesity and disease activity should be targeted for prevention of CVD in RA patients.

Assessing the correlation of insulin resistance with surrogate markers of atherosclerosis-like carotid artery intima-media thickness (CCA-IMT) or the presence of atherosclerotic plaque-Dessein and colleagues [61] found that QUICKI was associated with both IMT $(R=-0.26 ; P=0.04)$ and the presence of plaque $(P=0.03)$. In this group of RA patients ( $n=74$, mean age 55.8 years, $86 \%$ women), they found that the prevalence rates of MetS were 14\% according to WHO criteria and 19\% according to NCEP criteria. Only the WHOdefined MetS was associated with CCA-IMT $(P=0.08$ to 0.04 ), but overall both methods performed poorly in identifying RA patients with atherosclerosis.

Our team has studied the prevalence of MetS and its relationship with RA-associated factors in a group of middleto older-aged (mean age 63 years, $74 \%$ women) RA patients $(n=200)$ and compared them with 400 age- and gendermatched controls in the Mediterranean island of Crete. The prevalence of MetS (according to the NCEP criteria) was high (44\%) but comparable to that of the control population $(41 \%)$. Interestingly, in multivariate logistic regression analysis, the risk of having moderate to high disease activity (DAS28 >3.2) was significantly higher in patients with MetS compared with those without MetS (odds ratio 9.2, 95\% confidence interval 1.49 to 57 ), irrespective of the treatment [62]. This correlation between RA disease activity and MetS is indirect evidence of the role of chronic inflammation in MetS and atherosclerosis development. We are currently investigating the effect of potent anti-TNF- $\alpha$ treatment in insulin resistance in RA patients. After 3 months of treatment, patients with MetS at baseline $(n=31)$ improved significantly in both insulin resistance (HOMA, from $7.9 \pm 7.5$ to $2.6 \pm 1.6 ; P=0.01$ ) and insulin sensitivity (QUCKI, from $0.31 \pm 5.1$ to $0.35 \pm 4.4 ; P=0.03$ ) (P.I. Sidiropoulos, S.A. Karvounaris, D.T. Boumpas, unpublished data).

Chung and colleagues [63] studied MetS prevalence according to both WHO and NCEP criteria and its association to coronary atherosclerosis, applying electron beam computed tomography in a group of RA patients ( $n=154$, mean age 51 years for early RA and 59 years for established disease, $68 \%$ women) and compared them with controls. They found that, compared with controls, RA patients had a higher prevalence of WHO-defined 
Table 3

\begin{tabular}{|c|c|c|c|c|c|c|c|}
\hline & \multirow[b]{2}{*}{ Number } & \multirow{2}{*}{$\begin{array}{c}\text { Mean age, } \\
\text { years }\end{array}$} & \multirow{2}{*}{$\begin{array}{l}\text { Women, } \\
\text { percentage }\end{array}$} & \multicolumn{4}{|c|}{ Metabolic syndrome prevalence, percentage } \\
\hline & & & & NCEP & WHO & NCEP & WHO \\
\hline & \multicolumn{5}{|c|}{ Rheumatoid arthritis (RA) } & \multicolumn{2}{|c|}{ Control } \\
\hline Karvounaris, et al. [62] & 200 & 63 & 74 & 44 & - & 41 & - \\
\hline \multicolumn{8}{|l|}{ Chung, et al. [63] } \\
\hline Early RA & 88 & 51 & 64 & 30 & 31 & 22 & - \\
\hline Established RA & 66 & 59 & 73 & 42 & 42 & & \\
\hline \multirow[t]{2}{*}{ Dessein, et al. [61] } & 74 & 56 & 86 & - & 19 & - & - \\
\hline & \multicolumn{5}{|c|}{ Systemic lupus erythematosus } & \multicolumn{2}{|c|}{ Control } \\
\hline Chung, et al. [67] & 102 & 40 & 91 & 29 & 32 & 20 & 11 \\
\hline \multirow[t]{2}{*}{ Magadmi, et al. [66] } & 44 & 51 & 100 & 18 & - & - & - \\
\hline & \multicolumn{5}{|c|}{ Ankylosing spondylitis } & \multicolumn{2}{|c|}{ Control } \\
\hline Malesci, et al. [68] & 24 & 51 & 12 & 46 & - & 11 & - \\
\hline
\end{tabular}

NCEP, National Cholesterol Education Program; WHO, World Health Organization.

$(P=0.001)$ and NCEP-defined $(P=0.03)$ MetS; the prevalence rates of MetS (NCEP criteria) were $42 \%$ and $30 \%$ in patients with longstanding and early disease, respectively, not significantly different compared with $42 \%$ and $31 \%$ according to WHO criteria. Patients with WHOdefined MetS had an increased risk of having higher coronary artery calcification scores, independent of age and gender (odds ratio $=2 ; P=0.04$ ) [63].

Taken together, the studies by Karvounaris and colleagues [62] and Chung and colleagues [63] reported a high prevalence of MetS, albeit comparable to controls. The low prevalence in the report by Dessein and colleagues [61] may be attributed to demographic differences (lower age and higher percentage of women) or to the smaller sample size assessed (Table 3). From these studies, one can conclude that the prevalence of MetS is high in RA patients and correlates with disease activity and markers of atherosclerosis.

Adiponectin is one of the adipokines that has been described to increase insulin sensitivity, while there are data supporting that it has anti-inflammatory properties. As stated previously, low levels of adiponectin have been described in patients with T2DM or obesity [21]. It is believed that pro-inflammatory factors produced by adipose tissue suppress adiponection production and thus increase insulin resistance. Nevertheless, the relationship between adiponectin and inflammation seems to be more complex. In contrast to obesity, in diseases with chronic inflammation like RA and SLE, increased levels of adiponectin have been found, while in vitro data with chondrocytes and synovial fibroblasts suggest that adiponectin may exert pro-inflammatory effects $[64,65]$. These apparently controversial data pose more questions about the relationship between adiponectin, inflammation, and insulin signaling which should be addressed.

\section{Systemic lupus erythematosus}

El Magadmi and colleagues [66] assessed insulin resistance in a group of women with SLE $(n=44$, mean age 50.5 years) and compared them with age-matched controls. They found that SLE patients had significantly lower insulin sensitivity (HOMA-S; $P<0.01$ ), but HOMA-S did not correlate to disease activity or steroid therapy. The prevalence of MetS according to NCEP criteria in this small group was 18\%. On the other hand, Chung and colleagues [67] assessed MetS prevalence in an SLE cohort $(n=102$, mean age 40 years, $91 \%$ women) and compared them to age- and gendermatched controls $(n=101)$. Insulin resistance was more prevalent in patients (44\% versus $25 \% ; P=0.005)$ and the prevalence of the WHO-MetS was higher in patients $(32.4 \%$ versus $10.9 \% ; P<0.001)$. Although the NCEP-MetS was more prevalent in patients than controls, this was not statistically significant $(29.4 \%$ versus $19.8 \% ; P=0.14)$, probably because the study was underpowered to detect small differences. In this cohort, the presence of MetS correlated to higher CRP levels, but neither lupus activity nor damage scores were associated with MetS. The authors concluded that MetS is more prevalent in lupus patients, while the correlation of MetS with inflammatory markers underscores a possible common link between chronic inflammation and increased cardiovascular risk in SLE patients. 


\section{Ankylosing spondylitis}

A small $(n=24)$ controlled study by Malesci and colleagues [68] found that ankylosing spondylitis (AS) patients had a higher prevalence of NCEP-MetS compared with controls (45.8\% versus $10.5 \% ; P=0.02)$. In a cohort of AS male patients ( $n=63$, mean age 40 years) treated with anti-TNF- $\alpha$ agents, we investigated the prevalence of MetS according to NCEP criteria and compared the cohort to age-matched controls. MetS was more prevalent in AS patients (34.9\% versus 19\%; $P<0.01$ ), whereas AS patients with MetS had higher disease activity (Bath Ankylosing Spondylitis Activity Index; $P<0.05$ ) (P.I. Sidiropoulos, S.A. Karvounaris, D.T. Boumpas, manuscript submitted).

\section{Conclusion}

Patients with chronic inflammatory rheumatic diseases have an increased risk for CVD morbidity and mortality. In these patients, a high prevalence of traditional risk factors and MetS has been found. These data, albeit circumstantial, point out chronic inflammation as one of the key contributors to MetS and accelerated atherosclerosis. Aggressive treatment of both underlying disease-to lessen the inflammatory burden-as well as the elimination of traditional risk factors may reduce CVD morbidity and mortality. Assessment of both MetS along with the 10-year risk assessment for CVD events should be applied to identify patients in greater need for lifestyle modification and/or drug therapy.

\section{Competing interests}

The authors declare that they have no competing interests.

\section{Acknowledgments}

This work was supported by the FP6 European AUTOCURE program.

\section{References}

1. Reaven GM: Banting lecture 1988. Role of insulin resistance in human disease. Diabetes 1988, 37:1595-1607.

2. Barker DJ, Hales CN, Fall CH, Osmond C, Phipps K, Clark PM. Type 2 (non-insulin-dependent) diabetes mellitus, hypertension and hyperlipidaemia (syndrome $\mathrm{X}$ ): relation to reduced fetal growth. Diabetologia 1993, 36:62-67.

3. Reilly MP, Rader DJ: The metabolic syndrome: more than the sum of its parts? Circulation 2003, 108:1546-1551.

4. Alberti KG, Zimmet PZ: Definition, diagnosis and classification of diabetes mellitus and its complications. Part 1: diagnosis and classification of diabetes mellitus provisional report of a WHO consultation. Diabet Med 1998, 15:539-553.

5. Executive Summary of The Third Report of The National Cholesterol Education Program (NCEP) Expert Panel on Detection, Evaluation, And Treatment of High Blood Cholesterol In Adults (Adult Treatment Panel III). JAMA 2001, 285:2486-2497.

6. Alberti KG, Zimmet P, Shaw J: The metabolic syndrome-a new worldwide definition. Lancet 2005, 366:1059-1062.

7. Lakka HM, Laaksonen DE, Lakka TA, Niskanen LK, Kumpusalo E, Tuomilehto J, Salonen JT: The metabolic syndrome and total and cardiovascular disease mortality in middle-aged men. JAMA 2002, 288:2709-2716.

8. McNeill AM, Rosamond WD, Girman CJ, Golden SH, Schmidt MI, East HE, Ballantyne CM, Heiss G: The metabolic syndrome and 11-year risk of incident cardiovascular disease in the atherosclerosis risk in communities study. Diabetes Care 2005, 28: 385-390.

9. White MF, Kahn CR: The insulin signaling system. J Bio/ Chem 1994, 269:1-4.
10. Cusi K, Maezono K, Osman A, Pendergrass M, Patti ME, Pratipanawatr T, DeFronzo RA, Kahn CR, Mandarino LJ: Insulin resistance differentially affects the PI 3-kinase- and MAP kinase-mediated signaling in human muscle. J Clin Invest 2000, 105:311-320.

11. Uysal KT, Wiesbrock SM, Marino MW, Hotamisligil GS: Protection from obesity-induced insulin resistance in mice lacking TNF-alpha function. Nature 1997, 389:610-614.

12. Gupta D, Varma S, Khandelwal RL: Long-term effects of tumor necrosis factor-alpha treatment on insulin signaling pathway in HepG2 cells and HepG2 cells overexpressing constitutively active Akt/PKB. J Cell Biochem 2007, 100:593-607.

13. Senn JJ, Klover PJ, Nowak IA, Mooney RA: Interleukin-6 induces cellular insulin resistance in hepatocytes. Diabetes 2002, 51: 3391-3399.

14. Hennige AM, Stefan N, Kapp K, Lehmann R, Weigert C, Beck A, Moeschel K, Mushack J, Schleicher E, Häring HU: Leptin downregulates insulin action through phosphorylation of serine-318 in insulin receptor substrate 1. FASEB J 2006, 20:1206-1208.

15. Weisberg SP, McCann D, Desai M, Rosenbaum M, Leibel RL, Ferrante AW Jr.: Obesity is associated with macrophage accumulation in adipose tissue. J Clin Invest 2003, 112:1796-1808.

16. Miranda PJ, DeFronzo RA, Califf RM, Guyton JR: Metabolic syndrome: definition, pathophysiology, and mechanisms. Am Heart J 2005, 149:33-45.

17. Kahn CR, Flier JS, Bar RS, Archer JA, Gorden P, Martin MM, Roth $\mathrm{J}$ : The syndromes of insulin resistance and acanthosis nigricans. Insulin-receptor disorders in man. N Engl J Med 1976, 294:739-745.

18. Lebovitz HE, Banerji MA: Point: visceral adiposity is causally related to insulin resistance. Diabetes Care 2005, 28:2322-2325.

19. Mittelman SD, Van Citters GW, Kirkman EL, Bergman RN: Extreme insulin resistance of the central adipose depot in vivo. Diabetes 2002, 51:755-761.

20. Despres JP, Lemieux I: Abdominal obesity and metabolic syndrome. Nature 2006, 444:881-887.

21. Côté $M$, Mauriège $P$, Bergeron J, Alméras $N$, Tremblay $A$, Lemieux I, Després JP: Adiponectinemia in visceral obesity: impact on glucose tolerance and plasma lipoprotein and lipid levels in men. J Clin Endocrinol Metab 2005, 90:1434-1439.

22. Ford ES: Prevalence of the metabolic syndrome defined by the International Diabetes Federation among adults in the U.S. Diabetes Care 2005, 28:2745-2749.

23. Sarti C, Gallagher J: The metabolic syndrome: prevalence, CHD risk, and treatment. J Diabetes Complications 2006, 20: 121-132.

24. Flegal KM, Carroll MD, Ogden CL, Johnson CL: Prevalence and trends in obesity among US adults, 1999-2000. JAMA 2002, 288:1723-1727.

25. Sinha R, Fisch G, Teague B, Tamborlane WV, Banyas B, Allen K, Savoye M, Rieger V, Taksali S, Barbetta G, Sherwin RS, Caprio S: Prevalence of impaired glucose tolerance among children and adolescents with marked obesity. $N$ Engl J Med 2002, 346: 802-810.

26. Kahn R, Buse J, Ferrannini E, Stern M: The metabolic syndrome: time for a critical appraisal. Joint statement from the American Diabetes Association and the European Association for the Study of Diabetes. Diabetologia 2005, 48:1684-1699.

27. Wilson PW, D'Agostino RB, Parise H, Sullivan L, Meigs JB: Metabolic syndrome as a precursor of cardiovascular disease and type 2 diabetes mellitus. Circulation 2005, 112:3066-3072.

28. Kekalainen P, Sarlund H, Pyorala K, Laakso M: Hyperinsulinemia cluster predicts the development of type 2 diabetes independently of family history of diabetes. Diabetes Care 1999, 22: 86-92.

29. Isomaa B, Almgren P, Tuomi T, Forsén B, Lahti K, Nissén M, Taskinen MR, Groop L: Cardiovascular morbidity and mortality associated with the metabolic syndrome. Diabetes Care 2001, 24:683-689.

30. Malik S, Wong ND, Franklin SS, Kamath TV, L'Italien GJ, Pio JR, Williams GR: Impact of the metabolic syndrome on mortality from coronary heart disease, cardiovascular disease, and all causes in United States adults. Circulation 2004, 110:12451250.

31. Galassi A, Reynolds K, He J: Metabolic syndrome and risk of cardiovascular disease: a meta-analysis. Am J Med 2006, 119: 812-819. 
32. Sattar N, Gaw A, Scherbakova O, Ford I, O'Reilly DS, Haffner SM, Isles C, Macfarlane PW, Packard CJ, Cobbe SM, Shepherd J: Metabolic syndrome with and without $\mathrm{C}$-reactive protein as a predictor of coronary heart disease and diabetes in the West of Scotland Coronary Prevention Study. Circulation 2003, 108: 414-419.

33. Lorenzo C, Okoloise M, Williams K, Stern MP, Haffner SM: The metabolic syndrome as predictor of type 2 diabetes: the San Antonio heart study. Diabetes Care 2003, 26:3153-3159.

34. Klein BE, Klein R, Lee KE: Components of the metabolic syndrome and risk of cardiovascular disease and diabetes in Beaver Dam. Diabetes Care 2002, 25:1790-1794.

35. Bruno G, Merletti F, Biggeri A, Bargero G, Ferrero S, Runzo C, Prina Cerai S, Pagano G, Cavallo-Perin P; Casale Monferrato Study: Metabolic syndrome as a predictor of all-cause and cardiovascular mortality in type 2 diabetes: the Casale Monferrato Study. Diabetes Care 2004, 27:2689-2694.

36. Protopsaltis I, Korantzopoulos P, Milionis HJ, Koutsovasilis A, Nikolopoulos GK, Dimou E, Kokkoris S, Brestas P, Elisaf MS, Melidonis A: Metabolic syndrome and its components as predictors of ischemic stroke in type 2 diabetic patients. Stroke 2008, 39:1036-1038

37. Bertoni AG, Wong ND, Shea S, Ma S, Liu K, Preethi S, Jacobs DR Jr, Wu C, Saad MF, Szklo M: Insulin resistance, metabolic syndrome, and subclinical atherosclerosis: the Multi-Ethnic Study of Atherosclerosis (MESA). Diabetes Care 2007, 30: 2951-2966.

38. Alexander CM, Landsman PB, Teutsch SM, Haffner SM: NCEPdefined metabolic syndrome, diabetes, and prevalence of coronary heart disease among NHANES III participants age 50 years and older. Diabetes 2003, 52:1210-1214.

39. Yarnell JW, Patterson CC, Bainton D, Sweetnam PM: Is metabolic syndrome a discrete entity in the general population? Evidence from the Caerphilly and Speedwell population studies. Heart 1998, 79:248-252.

40. Kahn R, Buse J, Ferrannini E, Stern M: The metabolic syndrome: time for a critical appraisal: joint statement from the American Diabetes Association and the European Association for the Study of Diabetes. Diabetes Care 2005, 28:2289-2304.

41. Wilson PW, D'Agostino RB, Levy D, Belanger AM, Silbershatz $\mathrm{H}$, Kannel WB: Prediction of coronary heart disease using risk factor categories. Circulation 1998, 97:1837-1847.

42. Stevens RJ, Kothari V, Adler Al, Stratton IM: The UKPDS risk engine: a model for the risk of coronary heart disease in Type II diabetes (UKPDS 56). Clin Sci (Lond) 2001, 101:671-679.

43. Girman CJ, Rhodes T, Mercuri M, Pyörälä K, Kjekshus J, Pedersen TR, Beere PA, Gotto AM, Clearfield M; 4S Group and the AFCAPS/TexCAPS Research Group: The metabolic syndrome and risk of major coronary events in the Scandinavian Simvastatin Survival Study (4S) and the Air Force/Texas Coronary Atherosclerosis Prevention Study (AFCAPS/TexCAPS). Am J Cardiol 2004, 93:136-141.

44. Third Report of the National Cholesterol Education Program (NCEP) Expert Panel on Detection, Evaluation, and Treatment of High Blood Cholesterol in Adults (Adult Treatment Panel III) final report. Circulation 2002, 106:3143-3421.

45. Lakka TA, Laaksonen DE, Lakka HM, Männikkö N, Niskanen LK, Rauramaa R, Salonen JT: Sedentary lifestyle, poor cardiorespiratory fitness, and the metabolic syndrome. Med Sci Sports Exerc 2003, 35:1279-1286.

46. Chobanian AV, Bakris GL, Black HR, Cushman WC, Green LA, Izzo JL Jr., Jones DW, Materson BJ, Oparil S, Wright JT Jr., Roccella EJ; Joint National Committee on Prevention, Detection, Evaluation, and Treatment of High Blood Pressure. National Heart, Lung, and Blood Institute; National High Blood Pressure Education Program Coordinating Committee: Seventh report of the Joint National Committee on Prevention, Detection, Evaluation, and Treatment of High Blood Pressure. Hypertension 2003, 42:1206-1252.

47. Knowler WC, Barrett-Connor E, Fowler SE, Hamman RF, Lachin JM, Walker EA, Nathan DM; Diabetes Prevention Program Research Group: Reduction in the incidence of type 2 diabetes with lifestyle intervention or metformin. N Engl J Med 2002, 346:393-403

48. Gabriel SE, Crowson CS, Kremers HM, Doran MF, Turesson C, O'Fallon WM, Matteson EL: Survival in rheumatoid arthritis: a population-based analysis of trends over $\mathbf{4 0}$ years. Arthritis Rheum 2003, 48:54-58.
49. Hotamisligil GS: Inflammation and metabolic disorders. Nature 2006, 444:860-867

50. Boers M, Dijkmans B, Gabriel S, Maradit-Kremers H, O'Dell J, Pincus T: Making an impact on mortality in rheumatoid arthritis: targeting cardiovascular comorbidity. Arthritis Rheum 2004, 50:1734-1739.

51. Schattner A, Liang $M H$ : The cardiovascular burden of lupus: a complex challenge. Arch Intern Med 2003, 163:1507-1510.

52. Callahan LF, Pincus T: Mortality in the rheumatic diseases. Arthritis Care Res 1995, 8:229-241.

53. del Rincon ID, Williams K, Stern MP, Freeman GL, Escalante A: High incidence of cardiovascular events in a rheumatoid arthritis cohort not explained by traditional cardiac risk factors. Arthritis Rheum 2001, 44:2737-2745.

54. Bacon PA, Townend JN: Nails in the coffin: increasing evidence for the role of rheumatic disease in the cardiovascular mortality of rheumatoid arthritis. Arthritis Rheum 2001, 44:2707-2710.

55. Ward MM: Premature morbidity from cardiovascular and cerebrovascular diseases in women with systemic lupus erythematosus. Arthritis Rheum 1999, 42:338-346.

56. Sun SS, Shiau YC, Tsai SC, Lin CC, Kao A, Lee CC: The role of technetium-99m sestamibi myocardial perfusion singlephoton emission computed tomography (SPECT) in the detection of cardiovascular involvement in systemic lupus erythematosus patients with non-specific chest complaints. Rheumatology (Oxford) 2001, 40:1106-1111

57. Manzi S, Selzer F, Sutton-Tyrrell K, Fitzgerald SG, Rairie JE, Tracy RP, Kuller LH: Prevalence and risk factors of carotid plaque in women with systemic lupus erythematosus. Arthritis Rheum 1999, 42:51-60.

58. Esdaile JM, Abrahamowicz M, Grodzicky T, Li Y, Panaritis C, du Berger R, Côte R, Grover SA, Fortin PR, Clarke AE, Senécal JL: Traditional Framingham risk factors fail to fully account for accelerated atherosclerosis in systemic lupus erythematosus. Arthritis Rheum 2001, 44:2331-2337.

59. Dessein $\mathrm{PH}$, Stanwix AE, Joffe BI: Cardiovascular risk in rheumatoid arthritis versus osteoarthritis: acute phase response related decreased insulin sensitivity and high-density lipoprotein cholesterol as well as clustering of metabolic syndrome features in rheumatoid arthritis. Arthritis Res 2002, 4:R5.

60. Dessein $\mathrm{PH}$, Joffe $\mathrm{BI}$ : Insulin resistance and impaired beta cell function in rheumatoid arthritis. Arthritis Rheum 2006, 54: 2765-2775.

61. Dessein PH, Tobias M, Veller MG: Metabolic syndrome and subclinical atherosclerosis in rheumatoid arthritis. J Rheumatol 2006, 33:2425-2432.

62. Karvounaris SA, Sidiropoulos PI, Papadakis JA, Spanakis EK, Bertsias GK, Kritikos HD, Ganotakis ES, Boumpas DT: Metabolic syndrome is common among middle-to-older aged Mediterranean patients with rheumatoid arthritis and correlates with disease activity: a retrospective, cross-sectional, controlled, study. Ann Rheum Dis 2007 66:28-33.

63. Chung CP, Oeser A, Solus JF, Avalos I, Gebretsadik T, Shintani A, Raggi P, Sokka T, Pincus T, Stein CM: Prevalence of the metabolic syndrome is increased in rheumatoid arthritis and is associated with coronary atherosclerosis. Atherosclerosis 2008, 196:756-763.

64. Ehling A, Schäffler A, Herfarth $H$, Tarner IH, Anders S, Distler O, Paul G, Distler J, Gay S, Schölmerich J, Neumann E, MüllerLadner U: The potential of adiponectin in driving arthritis. $J$ Immuno/ 2006, 176:4468-4478.

65. Sada KE, Yamasaki $Y$, Maruyama M, Sugiyama H, Yamamura $M$, Maeshima $\mathrm{Y}$, Makino $\mathrm{H}$ : Altered levels of adipocytokines in association with insulin resistance in patients with systemic lupus erythematosus. J Rheumatol 2006, 33:1545-1552.

66. El Magadmi M, Ahmad Y, Turkie W, Yates AP, Sheikh N, Bernstein RM, Durrington PN, Laing I, Bruce IN: Hyperinsulinemia, insulin resistance, and circulating oxidized low density lipoprotein in women with systemic lupus erythematosus. J Rheumatol 2006, 33:50-56.

67. Chung CP, Avalos I, Oeser A, Gebretsadik T, Shintani A, Raggi P, Michael Stein C: High prevalence of the metabolic syndrome in patients with systemic lupus erythematosus: association with disease characteristics and cardiovascular risk factors. Ann Rheum Dis 2007, 66:208-214.

68. Malesci D, Niglio A, Mennillo GA, Buono R, Valentini G, La Montagna G: High prevalence of metabolic syndrome in patients with ankylosing spondylitis. Clin Rheumatol 2007, 26:710-714. 